\title{
Influence of Treatment on the Maturation of the Somesthetic Pathway in Infants with Primary Congenital Hypothyroidism during the First Year of Life
}

\author{
J. J. BONGERS-SCHOKKING, E. J. COLON, P. G. H. MULDER, R. A. HOOGLAND, \\ C. J. DE GROOT, AND J. L. VAN DEN BRANDE \\ Department of Pediatrics, Zuiderziekenhuis, Rotterdam [J.J.B.-S.]; Department of Psychiatrics, Delta Hospital, \\ Rotterdam [E.J.C.]; Department of Epidemiology and Biostatistics, Erasmus University, Rotterdam [P.G.H.M.]; \\ Department of Pediatrics, Emma Kinderziekenhuis-Kinder AMC, Academic Medical Centre, Amsterdam \\ [C.J.d.G.]; and Department of Pediatrics, University Hospital for Children and Youth "Het Wilhelmina \\ Kinderziekenhuis, "Utrecht, the Netherlands [J.L.V.d.B.]
}

\begin{abstract}
To assess the influence of treatment on the development of the somesthetic pathway in infants with congenital hypothyroidism receiving early treatment, median nerve somatosensory evoked potentials were measured during the 1st $y$ of life. Twenty-nine infants were studied with six to seven somatosensory evoked potential tests per infant. The cervical latency (N13) divided by arm length and the first (N19) and second (N32) cephalic latencies as well as N13-N32 latency were measured. At diagnosis, all components showed a small but significant delay, which was not related to thyroxine (T4) levels before treatment. During treatment, T4 ranged from 50 to $290 \mathrm{nmol} / \mathrm{L}$. At $12 \mathrm{mo}$, the cervical latency divided by arm length had normalized, whereas N19 and N13-N32 were more abnormal than at diagnosis. For N19, these abnormalities were related to a slow initial rise of T4 $(\leq 100 \mathrm{nmol} / \mathrm{L}$ after 1 wk of treatment) and the initial N19 values. Abnormal N13-N32 values were associated with high $\mathrm{T} 4$ values during treatment ( $>200 \mathrm{nmol} / \mathrm{L}$ ) and the type of congenital hypothyroidism (partial or total deficiency in T4 production). Induction of therapy with $l$-triiodothyronine rather than $l$-thyroxine and the occurrence of low T4 values $(<100$ $\mathrm{nmol} / \mathrm{L}$ ) after the 4th wk of therapy had no such effect. Our data suggest that, for normal CNS development, euthyroidism should be reached as soon as possible by adequate induction therapy. Thereafter, T4 supplementation should be strictly dosed, keeping the serum $\mathrm{T} 4$ values within narrow limits around the mean normal for age, because overtreatment, like initial undertreatment, may lead to CNS abnormalities at the end of the first year. (Pediatr Res 34: 73-78, 1993)
\end{abstract}

\section{Abbreviations}

CHT, congenital hypothyroidism

l-T4, levo-thyroxine

I-T3, levo-triiodothyronine

$l$-T4/f, fast initial serum $\mathrm{T} 4$ rise on $l$-T4 induction

$l$-T4/s, slow initial serum $\mathrm{T} 4$ rise on $l$-T4 induction

$\mathrm{PD}$, partial deficiency in $\mathrm{T} 4$ production

$\mathrm{TD}$, total deficiency in $\mathrm{T} 4$ production

Received June 7, 1991; accepted February 1, 1993.

Correspondence: J. L. Van den Brande, Department of Pediatrics, University Hospital for Children and Youth "Het Wilhelmina Kinderziekenhuis," Nieuwe Gracht 137, 3512 LK Utrecht, the Netherlands.

Supported by Grant 28-1005 of the Prevention Fund, Den Haag, the Netherlands.
PMA, postmenstrual age

SEP, somatosensory evoked potentials

N13/AL, latency to first negative peak in cervical lead divided by arm length

N19, latency to first negativity in cephalic lead

$\mathrm{N} 32$, latency to second negativity in cephalic lead

$\mathrm{N} 60$, latency to third negativity in cephalic lead

P22, latency to first positivity after N19

$\mathrm{T} 4>200$, group with serum $\mathrm{T} 4>200 \mathrm{nmol} / \mathrm{L}$ on all occasions

$\mathrm{T} 4<200$, group with serum $\mathrm{T} 4<200 \mathrm{nmol} / \mathrm{L}$ on all occasions

b1, slope for period $\mathrm{T} 4<200 \mathrm{nmol} / \mathrm{L}$

b2, slope for period $\mathrm{T} 4>200 \mathrm{nmol} / \mathrm{L}$

The major objective of the national screening programs for CHT is the prevention of neurologic damage. On the whole, the results of the screening seem gratifying, but there are still unsatisfying aspects. Several studies $(1-3)$ report CHT infants displaying minor neurologic dysfunctions and subnormal IQ at later age despite early diagnosis and treatment. Other studies report normal findings (4-6).

Generally, the neurologic deficits are ascribed to perinatal thyroid hormone deficiency, because they were found to be related to very low initial T4 values and/or severely retarded bone age $(1,2)$. However, they may also result from inadequate T4 supplementation (7-9). Cortical development is maximal during the first 3 extrauterine mo and abnormal thyroid hormone levels during this phase may interfere with normal CNS development. Besides undertreatment, overtreatment also should be considered as potentially harmful $(8,9)$.

The aim of our study was to document the maturation of the somesthetic pathway in CHT infants during the 1st y of life and to evaluate the influence of treatment. We followed longitudinally 29 CHT patients with median nerve SEP. SEP abnormalities were expected on the basis of earlier evoked potential studies in CHT infants $(10-13)$. SEP results were related to treatment factors such as induction of therapy with $l-\mathrm{T} 4$ or $l-\mathrm{T} 3$, slow or fast rise of T4 during induction of therapy, and subsequent T4 values above or below the normal range as well as to factors not directly related with treatment such as type of CHT, prematurity, and hyperbilirubinemia. As it was a prospective, longitudinal study, both immediate and late effects on SEP results could be examined. 


\section{SUBJECTS AND METHODS}

CHT infants. From July 1986 to December 1987, 37 patients were referred to us for SEP examination because of abnormal CHT screening results in the national screening program. Four patients were excluded from the study because the diagnosis of primary CHT was not confirmed (thyroid binding globulin deficiency, transient hypothyroxinemia, secondary CHT), and another four patients were excluded because of additional abnormalities (Down's syndrome, Duchenne's muscular dystrophy) or lack of parental cooperation.

The remaining 29 infants (19 girls, 10 boys) were studied longitudinally. They remained under the care of the local pediatrician. The group consisted of 26 term infants (gestational age 36.5 to $43 \mathrm{wk}$ ) and three preterm patients (gestational age 34 to 35.5 wk). Birth weight ranged from 1910 to $4250 \mathrm{~g}$. One infant was delivered by cesarean section. One preterm patient was the second infant of a dizygotic twin pair. One infant needed a short period of assisted ventilation. Bilirubin concentrations above 250 $\mu \mathrm{mol} / \mathrm{L}$ during the $1 \mathrm{st}$ wk occurred in four term infants and in the three preterm patients.

Type of CHT. Fourteen patients had a TD due to either an agenesis of the thyroid gland $(n=9)$ or to a total block in thyroid hormone production $(n=5)$. Fifteen infants had a PD: they had either an ectopic thyroid gland $(n=2)$ or a partial enzyme block $(n=3)$. Patients were classified according to diagnostic criteria described previously (14). The procedure included measurement of thyroid hormone, thyroid binding globulin, and thyroglobulin levels in serum as well as levels of low-molecular-weight iodinated material in urine, scintigraphy and/or ultrasonography of the thyroid gland, and, on indication, a radioactive iodine uptake test. Initial T4 (T4 before treatment) was $13 \pm 7 \mathrm{nmol} / \mathrm{L}$ (mean $\pm 1 \mathrm{SD}$ ) in the TD group and $60 \pm 33 \mathrm{nmol} / \mathrm{L}$ in the PD group.

Induction of therapy. Age at the onset of therapy ranged from 13 to $28 \mathrm{~d}$ (median $18 \mathrm{~d}$ ). Induction was started with either $l$-T4 $(n=21)$ or $l$-T3 $(n=8)$. This choice, as well as all other decisions about therapy, were made by the local pediatricians without knowledge of the SEP results.

Group l-T3 contained four TD and four PD patients. l-T3 induction was accomplished by $l-\mathrm{T} 3$ monotherapy during the $1 \mathrm{st}$ 0.5 to $1.5 \mathrm{wk}$ in progressive dosages from 1 to $3 \mu \mathrm{g} / \mathrm{kg} / \mathrm{d}$. $l-\mathrm{T} 4$ was then gradually added with reduction of $l-\mathrm{T} 3$ dosage. After 2.5 to $3 \mathrm{wk}$, all infants were on $l$-T 4 monotherapy, with a peak dosage of $8 \mu \mathrm{g} / \mathrm{kg} / \mathrm{d}$ at 4 to $5 \mathrm{wk}$.

Group l-T4 was subdivided into two groups: $l-\mathrm{T} 4 / \mathrm{f}(n=12$; three TD and nine PD) and $l-\mathrm{T} 4 / \mathrm{s}(n=9$; eight TD and one PD) according to whether, after $7 \mathrm{~d}$ of therapy, serum T4 levels were above or below (or equal to) $100 \mathrm{nmol} / \mathrm{L}$. Some of the values were obtained by linear interpolation as described previously (10). T4 levels of the $l$-T 4 groups differed only at wk 0,1 , and $2(p<0.025)$. Both groups started on a comparable l-T4 dose: $5.8 \pm 0.9$ and $6.8 \pm 1.6 \mu \mathrm{g} / \mathrm{kg} / \mathrm{d}$, respectively $(6 \mu \mathrm{g} / \mathrm{kg}=$ $\sim 100 \mu \mathrm{g} / \mathrm{m}^{2}$ ). The peak dosage of group $l-\mathrm{T} 4 / \mathrm{s}$ (nearly $8 \mu \mathrm{g} / \mathrm{kg} /$ d) was at wk 3; that of group $l-\mathrm{T} 4 / \mathrm{f}$ (just above $6 \mu \mathrm{g} / \mathrm{kg} / \mathrm{d}$ ) was at wk 1 .

T4 and TSH determinations. Per patient, 10-17 T4 determinations were made (median 14), almost always in combination with a TSH measurement. They were made in the local hospitals. In some cases, only free T4 (FT4) levels were provided. They were transformed to T4 values using the following formula: T4 $(\mathrm{nmol} / \mathrm{L})=8.1 \cdot \mathrm{FT} 4(\mathrm{pmol} / \mathrm{L})$, which was derived from 47 instances in which both T4 and FT4 were determined.

T4 levels above or below normal range. The normal range of T4 levels for infants from 1 to $3 \mathrm{mo}$ is 100 to $200 \mathrm{nmol} / \mathrm{L}$ (mean $150 \mathrm{nmol} / \mathrm{L}$ ); from 3 to $12 \mathrm{mo}$ it is 100 to $180 \mathrm{nmol} / \mathrm{L}$ (mean $140 \mathrm{nmol} / \mathrm{L})(15-17)$. After the induction period, serum T4 levels of our patients ranged from 50 to $290 \mathrm{nmol} / \mathrm{L}$.

Seven patients (three PD and four TD) reached T4 levels $<100$ $\mathrm{nmol} / \mathrm{L}$. This occurred at a median age of $33 \mathrm{wk}$ (range 7 to 41 ); duration of this low T4 state was $11.4 \pm 7.1$ wk.

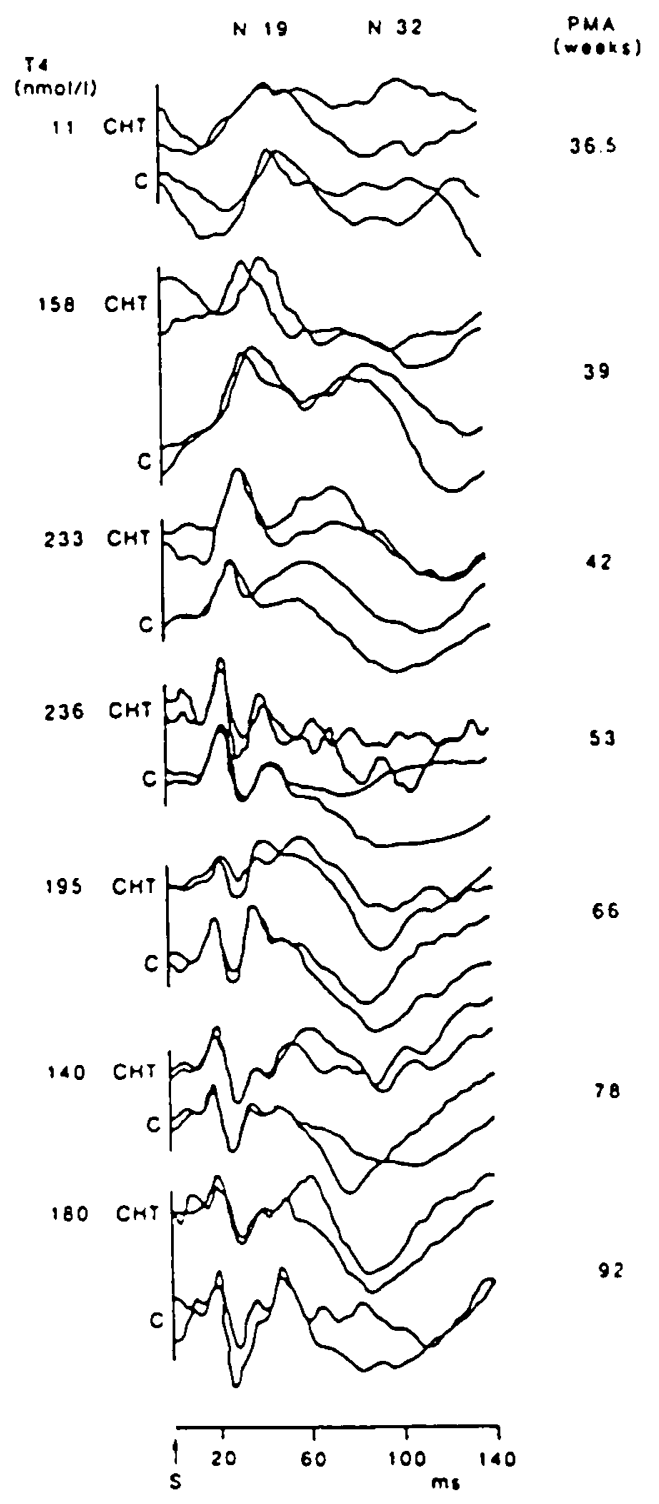

Fig. 1. Maturation of cephalic SEP (N19 and N32 are indicated) during 1st $y$ of two preterm twin sisters: one with CHT, the other normal $(C)$. Results of right and left side are superimposed. $S$, stimulus; Upwards means negative. PMA at birth $=34 \mathrm{wk}, \mathrm{l}$-T3 induction. Note that N19 of the CHT infant is first normal, at 42 wk abnormal, and at 92 wk close to normal. N32 normalizes in the period from 42 to $53 \mathrm{wk}$ under high T4 levels; thereafter, its maturation slows down.

In 21 patients ( 12 TD and nine PD), T4 levels reached $>200$ $\mathrm{nmol} / \mathrm{L}$ on one or more occasions. This occurred for the first time at a median age of $8 \mathrm{wk}$ of therapy (range 2 to $28 \mathrm{wk}$ ). Median duration of all T4>200 periods together was $4.5 \mathrm{wk}$ for the PD patients and $11.9 \mathrm{wk}$ for the TD infants (significant difference, $\mathrm{T}_{\mathbf{S}}=156, p<0.05$, Wilcoxon's rank test). From 2 to $5 \mathrm{wk}$, the T4>200 group received a larger $l-T 4$ dosage than the T $4<200$ group $(p<0.02)$. Serum T4 values were different from 5 to 6 to 25 weeks $(p<0.05)$.

SEP examinations. Cervical (CS2-Fz) and cephalic (C3'/C4'$\mathrm{Fz}$ ) SEP were recorded as described previously (19). The temperature of the arms was kept constant with a thermocouple, ensuring a near-nerve temperature of 36 to $38^{\circ} \mathrm{C}$. Both median nerves were stimulated separately. For each recording, the results of 25 to 100 stimuli were averaged, using a $2-$ to $100-\mathrm{Hz}$ as well as a 2 - to $2000-\mathrm{Hz}$ filter bandpass ( $-6 \mathrm{~dB} /$ octave) (18). All calculations were performed using the results of the $2-$ to $100-\mathrm{Hz}$ bandpass. Latencies from the beginning of the stimulus to the top of the first negativity in the cervical leads (N13) and to the 
Table 1. SEP and thyroid hormone data of CHT infants*

\begin{tabular}{|c|c|c|c|c|c|c|c|c|c|c|c|}
\hline PMA (wk) & $\begin{array}{l}\text { Wk after } \\
\text { onset of } \\
\text { therapy }\end{array}$ & $n$ & \multicolumn{2}{|c|}{ N13/AL } & \multicolumn{2}{|c|}{ N19 } & \multicolumn{2}{|c|}{ N13-N32 } & $\begin{array}{c}\mathrm{T} 4 \\
(\mathrm{nmol} / \mathrm{L})\end{array}$ & \multicolumn{2}{|c|}{ TSH } \\
\hline $43.3 \pm 3.0$ & $0.3 \pm 0.4$ & 24 & $53.2 \pm 5.7$ & $1.0 \pm 0.7 \dagger$ & $31.0 \pm 7.9$ & $1.0 \pm 0.9 \dagger$ & $52.9 \pm 15.7$ & $0.6 \pm 0.9 \ddagger$ & $56 \pm 45$ & $>250$ & $30-1380$ \\
\hline $46.3 \pm 3.2$ & $4.2 \pm 1.1$ & 10 & $50.9 \pm 4.4$ & $1.1 \pm 0.8 \dagger$ & $29.0 \pm 3.5$ & $1.5 \pm 0.7 \dagger$ & $45.4 \pm 7.8$ & $0.5 \pm 0.8$ & $135 \pm 63$ & 23 & $0.5-250$ \\
\hline $54.2 \pm 1.4$ & $10.8 \pm 3.0$ & 29 & $40.9 \pm 2.3$ & $0.2 \pm 1.0$ & $23.9 \pm 1.2$ & $1.4 \pm 0.8 \dagger$ & $34.8 \pm 2.5$ & $0.2 \pm 0.8$ & $171 \pm 38$ & 7 & $0.3-94$ \\
\hline $67.5 \pm 1.9$ & $24.2 \pm 3.1$ & 28 & $35.4 \pm 2.1$ & $0.2 \pm 1.2$ & $21.4 \pm 1.2$ & $1.5 \pm 1.2 \dagger$ & $30.3 \pm 2.1$ & $0.5 \pm 1.1$ & $149 \pm 33$ & 11 & $0.3-164$ \\
\hline
\end{tabular}

* Values are expressed as mean \pm SD. SDS, standard deviation score.

$\dagger p<0.001$, significantly different from normal population.

$\ddagger p<0.05$, significantly different from normal population.

$\S p<0.01$, significantly different from normal population.

top of the first (N19) as well as the second (N32) negativity in the cephalic leads were measured. For each parameter, the results of the right and left side were averaged. N13-N32 interpeak latency was used as the indicator for central conduction, N13/ $\mathrm{AL}$ for peripheral conduction (19), and N19 for both central and peripheral conduction.

SEP examinations were done at or within 1 wk after the onset of therapy $(n=23)$, approximately 2 wk later $(n=28)$, approximately 4 wk later $(n=10)$, and at $3(n=29), 6(n=28), 9(n$ $=27)$, and $12 \mathrm{mo}(n=29)$. All tests were performed by one investigator (J.J.B.-S.). T4 and TSH values were obtained at or within $1 \mathrm{~d}$ of the examination day for the first three SEP tests; for the later tests, they were obtained within $7 \mathrm{~d}$ of the examination day. Informed consent was obtained from the parents. The project was approved by the ethical committee of the Zuiderziekenhuis, Rotterdam, the Netherlands.

Reference population. Reference SEP values were obtained from 144 examinations of 115 normal infants. Gestational age ranged from 25.5 to $43 \mathrm{wk}$ and postnatal age from 0 to $56 \mathrm{wk}$. The selection and exclusion criteria for this reference group have been described previously (10). In essence, only infants in good physical health, admitted to the pediatric ward for nonneurologic reasons, were included. Patients with major malformations, chromosomal abnormalities, serious illnesses, perinatal pathology, and abnormal thyroid screening results were excluded.

Statistical analysis. For the reference SEP data, the relation with PMA was determined. Linearity of the regression lines was obtained by logarithmic transformation of both PMA and SEP values. CHT SEP values were expressed as SD score of the reference population, using the following formula: $S D=$ (SEPpat - SEPref)/SDref, where SEPpat is the measured SEP value, SEPref is the mean SEP value of reference population at the same age, and SDref is the SD of reference population.

$A$ one-level analysis of variance was used for comparison of mean values of groups.

To compare trends, a repeated-measurements analysis of variance was performed, using program $5 \mathrm{~V}$ of the BMDP package (20). From the four to seven measurements per patient (median, six), the linear trend of the dependent variable (SEP values) with time was estimated. For groups $l-\mathrm{T} 4 / \mathrm{f}, l-\mathrm{T} 4 / \mathrm{s}$, and $l-\mathrm{T} 3$, the linear trends from the first to the last test were compared, using a random coefficient model. The SEP values of group $T 4>200$, on visual inspection, showed a trend breakage just after the age at which serum T4 exceeded the level of $200 \mathrm{nmol} / \mathrm{L}$ for the first time. This age varied for each patient (median, $12 \mathrm{wk}$ ). The between-patients means of the trends before (b1) and after this age (b2) were estimated and compared, using two time variables as covariates. In both models, the type of CHT (PD/TD) was included as a covariable. If, in the latter model, the variances of the error term clearly showed an increase with age, an unstructured covariance matrix of the error term was specified in the model. Otherwise, a banded covariance matrix was specified.

Multiple regression analysis was applied to the SEP values at
12 mo to identify the contribution of various factors to the SEP values at this age.

\section{RESULTS}

SEP Wave Form. All maturational features of the SEP of normal infants were also present in the SEP of the CHT patients (Fig. 1), although in the latter group, the wave complexes were sometimes less stable, and the amplitude of the waves more variable. From 36 to 100 wk PMA, the shape of the N13 complex remained relatively unchanged, whereas that of the cephalic wave complex underwent important changes. The cephalic peaks showed fast maturation, N19 between 36 and 44 wk and N32 between 44 and 52 wk PMA. During the second part of the 1st $y$, a third negative peak, N60, developed and partly obscured the N32 peak. The N32 remained visible as a shoulder in the ascending part of the N60.

SEP Latencies. At onset of therapy, all SEP latencies were slightly prolonged in comparison to the reference population (Table 1). Initial SEP values were not related to initial T4. Under therapy, N13/AL and N13-N32 normalized and were in the normal range at $3 \mathrm{mo}$. From then on, the N13/AL remained normal. In contrast, the decrease of the N13-N32 was less than normal, resulting in prolonged latencies at $12 \mathrm{mo}(p<0.001)$. N19 remained slightly abnormal during the whole study period and, like N13-N32, ranged largely around the $+2 \mathrm{SD}$ of the reference population at $12 \mathrm{mo}$.

$\mathrm{N} 19$ at 12 mo correlated with the initial N19 $(r=0.53, p<$ 0.01 ). For N13/AL and N13-N32, such correlations were not found. When all measurements $(n=184)$ were taken together, T4 and TSH showed no correlation with N13/AL, N19, or N13N32 after correction for multiple observations per patient.

Longitudinal Assessments. Groups l-T4/s, l-T4/f, and l-T3 (Fig. 2, Table 2). SEP values of the three groups at diagnosis were comparable. The N13/AL and N13-N32 values showed no significant differences in trend. In contrast, the N19 trend of the l-T4/s group and that of the two other groups differed significantly, with a steeper slope for the first group. The type of CHT was not a disturbing factor in this model (data not shown).

Groups T4<200 and T4>200 (Fig. 3, Table 2). For all SEP parameters, $b 1$ and $b 2$ values were significantly different. The $\mathrm{N} 13 / \mathrm{AL}$ b1 slope was negative; the b2 slope was close to zero. In contrast, b1 values of $\mathrm{N} 19$ and N13-N32 were close to zero, whereas the corresponding $b 2$ values were clearly positive. This indicates for N13/AL first a normalization, thereafter a stabilization; for N19 and N13-N32 it indicates first a stabilization, thereafter a deviation from the baseline. TD/PD did not influence the slopes and intercepts significantly.

Multiple regression analysis at $12 \mathrm{mo}$ (Table 3). For N13/AL, no regression was obtained with the tested factors. For N19 and N13-N32, the regressions were highly significant $(R=0.83$ and $R=0.75, p<0.001$ for both). l-T4/s and the initial N19 value were the factors contributing to the N19 regression; for N13- 

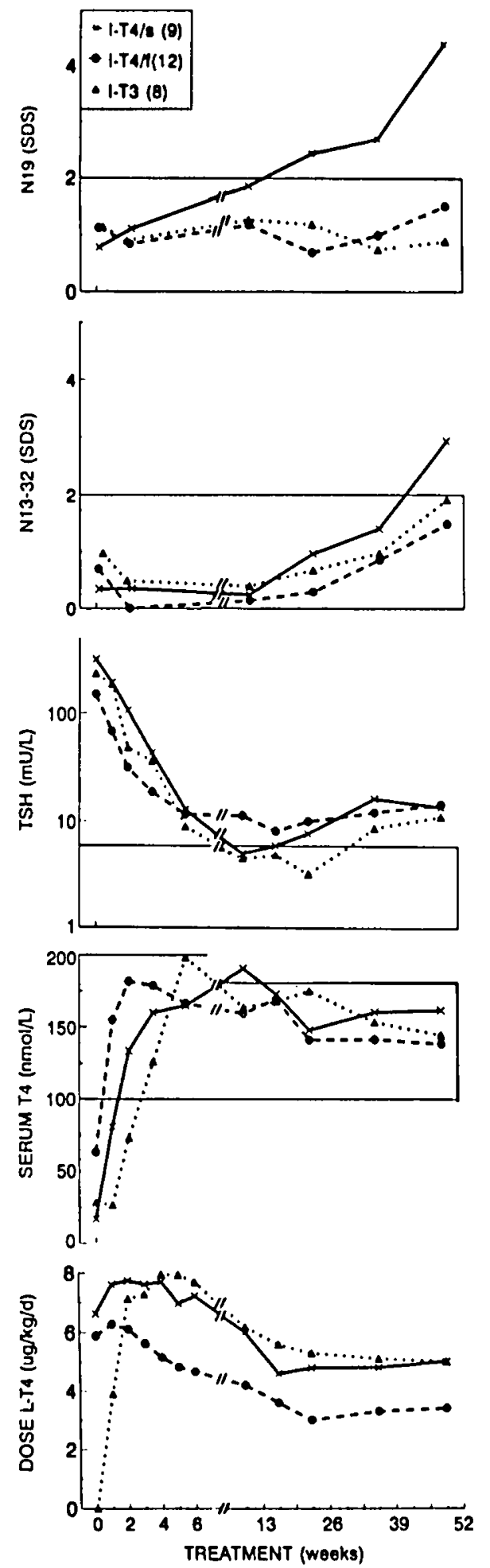

Fig. 2. Dosage of $l-T 4(L-T 4)$, thyroid hormone levels, and SEP data of three CHT groups: on l-T4 induction with slow (s) or fast (f) serum $\mathrm{T} 4$ rise and on $l-\mathrm{T} 3$ induction. Framed areas, normal ranges; $S D S$, standard deviation score.

N32, T4>200 and type of CHT were determining factors, with T4>200 being the more important one $(p<0.001)$. Hyperbilirubinemia during the $1 \mathrm{st} \mathrm{wk}$, prematurity, $l-\mathrm{T} 3$ induction, or $\mathrm{T} 4$ $<100 \mathrm{nmol} / \mathrm{L}$ did not contribute to any of the regressions.

\section{DISCUSSION}

Registration of SEP provides a sensitive indicator for the maturity and integrity of the somesthetic pathway from periphery
Table 2. Estimates of regression parameters of CHT-SEP values with age*

\begin{tabular}{|c|c|c|c|c|}
\hline & N13/AL & N19 & N13-N32 & \\
\hline \multicolumn{5}{|l|}{ Intercept $\dagger$} \\
\hline$l-\mathrm{T} 4 / \mathrm{s}$ & 0.63 & 0.79 & -0.17 & \\
\hline Others & 0.71 & 0.91 & 0.13 & \\
\hline All patients & 0.67 & $0.85 \ddagger$ & -0.03 & \\
\hline \multicolumn{5}{|l|}{ Slope $\dagger$} \\
\hline l-T4/s & -1.26 & $5.97]_{+}$ & 4.66 & \\
\hline Others & -1.52 & $0.21]^{f}$ & 2.41 & \\
\hline All patients & -1.39 & $3.09 \ddagger$ & $3.53 \ddagger$ & \\
\hline \multicolumn{5}{|l|}{ Intercept§ } \\
\hline TD & 0.80 & 1.21 & 0.32 & \\
\hline PD & 0.67 & 0.89 & 0.27 & \\
\hline All patients & $0.73 \ddagger$ & $1.03 \ddagger$ & 0.30 & \\
\hline \multicolumn{5}{|l|}{ Coeff. bl§ } \\
\hline TD & -3.29 & 0.15 & 0.99 & \\
\hline PD & -3.25 & 1.28 & 0.73 & \\
\hline All patients & $-3.27]$ & $0.74]$ & $0.86]$ & \\
\hline \multicolumn{5}{|l|}{ Coeff, b2\| } \\
\hline TD & $0.16 \ddagger$ & $4.32 \neq$ & 6.27 & $\ddagger$ \\
\hline PD & 0.40 & 1.35 & 4.14 & \\
\hline All patients & 0.28 & 2.84 & 5.20 & \\
\hline
\end{tabular}

*Intercept, in SDS; coefficients, in SDS/wk $10^{2}$. Grouping as indicated. SDS, standard deviation score.

$\dagger$ From first till last SEP test.

$\ddagger p<0.001$, significantly different from zero or from indicated value.

$\S$ For period $\mathrm{T} 4<200$

\| For period from T4 $>200$ for first time till last test.

to cortex. The results of our reference group are in close agreement with those of other authors (21). Measurement of the N13/ $\mathrm{AL}$ gives information about the conduction properties of the peripheral nerve and the dorsal column. The cephalic components (N19, N32) are thought to derive from subcortical and cortical sources. The rapid and sequential maturation of the various parts of the cortex from 1 mo before birth to 3 to 6 mo postnatally is reflected by the SEP in the successive appearance of N19, P22, N32, and N60.

Thyroid hormones interfere with many of the processes that underlie cortical maturation. SEP abnormalities such as were found in CHT patients at the onset of treatment could therefore be expected. Other evoked potential studies on the somesthetic and visual pathways showed similar results $(12,13)$. A study on the peripheral nerves (22) demonstrated depressed nerve conduction velocities at initiation of therapy. However, SEP delay was less severe than bone age delay (10). The transplacental transfer of T4 (23) probably protects the CHT fetus and, in particular, the CNS from most of the damage from depressed fetal T4 levels (10).

Under therapy, the maturation of the SEP pathway did not proceed in a uniform way: the peripheral component normalized, whereas the cephalic components were more abnormal at 12 mo than at initiation of therapy. This agrees with the data of Laureau et al. $(12,24)$, who also found normal N13 latencies in treated CHT infants at the age of 6 and $18 \mathrm{mo}$, but abnormalities in the N19, P22, and N19-P22 latencies. This dissimilarity among the various parameters may have been caused by a different timing of the critical periods of the various parts of the pathway. N13 is already visible at 30 wk PMA (25), well ahead of N19; N13/AL was not influenced by differences in treatment regimen. In contrast, N19 was affected by induction factors, such as a slow initial T4 rise, whereas induction with $l-\mathrm{T} 3$ appeared to prevent a further delay. Furthermore, N19 values at 12 mo were related to initial N19 values, suggesting that a maturational delay in this period is more or less permanent. In contrast, N13-N32 was affected mainly by the later-occurring T4>200. Interestingly, peak $\mathrm{T} 4$ values coincided with the period when $\mathrm{N} 32$ experiences its rapid maturation. 

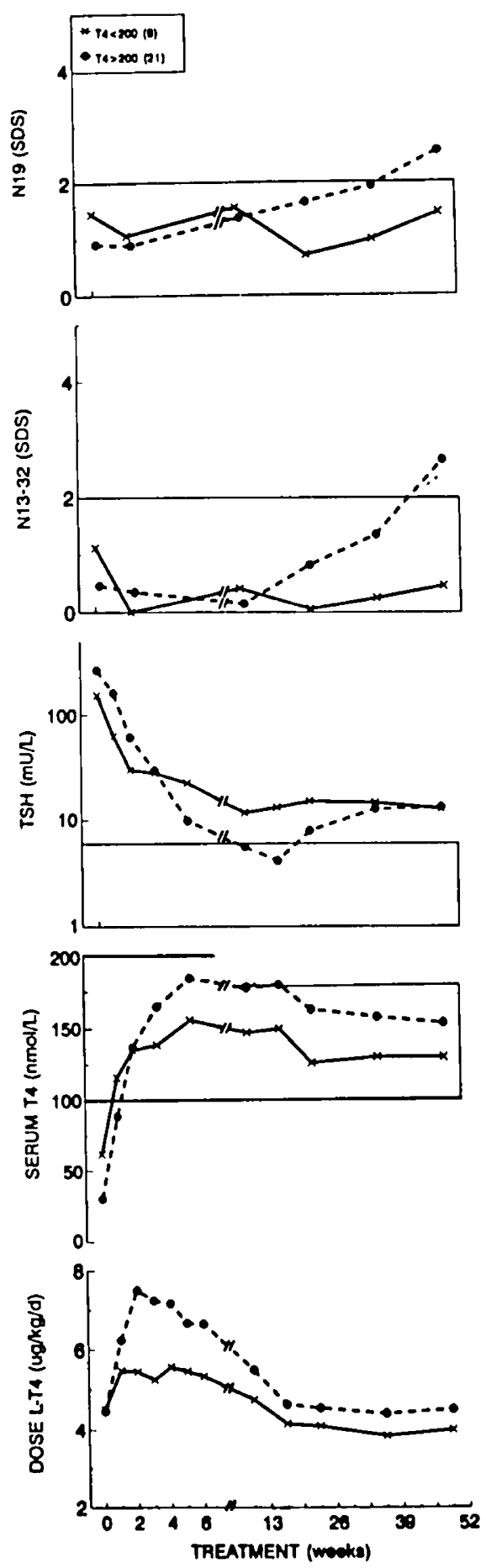

Fig. 3. Dosage of $l$-T4 (L-T4), thyroid hormone levels, and SEP data of CHT groups without $(\mathrm{T} 4<200)$ or with $(\mathrm{T} 4>200)$ serum T4 levels $>200 \mathrm{nmol} / \mathrm{L}$. Framed areas, normal ranges; SDS, standard deviation score.

In view of the recent demonstration that serum T3 does not enter the brain of fetal rats near term (26), it is remarkable that, in our study, $l-\mathrm{T} 3$ induction seemed to prevent the adverse effects of a slow initial T4 rise. Clinically, these infants improved promptly after the first $l$-T3 dose. In 10-d-old (27) and in adult rats (28), serum T3 has access to the brain. This suggests that the accessability of peripheral T3 to the CNS is age-dependent.

Our study suggests that adequate early treatment of $\mathrm{CHT}$ patients is crucial for normal CNS development. The importance of adequate induction is also supported by developmental studies in older CHT children. Normal IQ scores and normal school
Table 3. Multiple regression analysis for SEP values at $12 \mathrm{mo}^{*}$

\begin{tabular}{|c|c|c|c|c|c|c|c|c|}
\hline \multirow{3}{*}{$\begin{array}{c}\text { Independent } \\
\text { variable }\end{array}$} & \multicolumn{8}{|c|}{ Dependent SEP variable at $12 \mathrm{mo}$} \\
\hline & \multicolumn{2}{|c|}{ N13/AL } & \multicolumn{3}{|c|}{ N19 } & \multicolumn{3}{|c|}{$\mathrm{N} 13-32$} \\
\hline & B & $p$ & B & SE B & $p$ & B & SE B & $p$ \\
\hline Intercept & & & 0.17 & & & -0.09 & & \\
\hline EHB & & NS & & & NS & & & NS \\
\hline Initial SEP value & & NS & 1.20 & 0.27 & $<0.001$ & & & NS \\
\hline l-T3 & & NS & & & NS & & & NS \\
\hline /.T $4 / \mathrm{s}$ & & NS & 3.04 & 0.48 & $<0.001$ & & & NS \\
\hline $\mathrm{T} 4>200$ & & NS & & & NS & 2.19 & 0.48 & $<0.001$ \\
\hline $\mathrm{T} 4<100$ & & NS & & & NS & & & NS \\
\hline TD & & NS & & & NS & 1.12 & 0.40 & 0.010 \\
\hline$R$ & 0.00 & NS & 0.83 & & $<0.001$ & 0.75 & & $<0.001$ \\
\hline
\end{tabular}

* B, coefficient; SE B, standard error of B; EHB, bilirubin $>250 \mu \mathrm{mol} /$ $\mathrm{L}$ in $1 \mathrm{st} \mathrm{wk} ; \mathrm{T} 4<100$, serum $\mathrm{T} 4<100 \mathrm{nmol} / \mathrm{L}$ on one or more occasions after T4 measurement(s) $>100 \mathrm{nmol} / \mathrm{L} ; R$, regression coefficient. For $R$, only the significant variables were included.

performances were obtained in those studies in which the patients received a high initial dosage of $l-\mathrm{T} 4$ (8 to 10 or $10 \mu \mathrm{g} / \mathrm{kg} / \mathrm{d})(4-$ $6,29)$. In those studies in which a lower induction regimen was given comparable to that of our study (1-3), however, subnormal IQ scores and developmental delays were found, especially for the TD patients. This indicates that TD patients also may have a normal development when adequately treated. This corroborates our data. Treatment factors, but not factor TD, were major determining factors in the regression analysis at $12 \mathrm{mo}$ and in the trend analysis. This stresses the need for adequate treatment, especially in the TD patients.

In determining the initial dosage, it is good to realize that the need for T4 is high in the neonate. Dosages of 10 to $15 \mu \mathrm{g} / \mathrm{kg} / \mathrm{d}$ are said to achieve serum T4 levels above $100 \mathrm{nmol} / \mathrm{L}$ within 1 wk in practically all patients $(7,30)$, whereas dosages of $5 \mu \mathrm{g} / \mathrm{kg} /$ $\mathrm{d}$ in severely hypothyroid patients hardly raise serum $\mathrm{T} 4$ levels $(31,32)$. Adult substitution therapy is about 2 to $2.5 \mu \mathrm{g} / \mathrm{kg} / \mathrm{d}$ (32). It is likely that the neonatal CNS accounts for the largest part of this high $\mathrm{T} 4$ requirement, due to its relative large mass (13.5 versus $2.5 \%$ in the adult) and its elevated T 4 metabolism in comparison with the adult $(26,33-35,38)$. Probably, the CNS is by far the most important T4 metabolizing organ in the neonatal period. Low serum concentrations of $\mathrm{T} 4$ will be leveled out by enhanced activity of the CNS iodothyronine $5^{\prime}$-deiodinase type II deiodination in combination with reduced activity of the iodothyronine 5'-deiodinase type III system. Too-low T4 concentrations, however, over a longer period will affect cerebral thyroid status and thus its development. In view of the normal $\mathrm{T} 4$ range, one may suppose that with levels $>100 \mathrm{nmol} / \mathrm{L}$ the CNS requirements for T4 are met, and we have no indications that, for normal CNS development, serum T4 should be above the mean normal for age. Peaks $>200 \mathrm{nmol} / \mathrm{L}$ should be avoided. Recently, it was reported that high T4 levels during the early phase of CHT treatment induced behavioral problems around the age of $6 \mathrm{mo}$, which lasted up to approximately 2 y (9). Hyperthyroidism in the postnatal period $(36,37)$ and overtreatment of CHT infants (8) lead to advanced physical maturation, whereas at a later age, intellectual performance is often impaired, probably as the result of a decreased connectability in the CNS. A 4-d period of $l$-T4 administration to normal neonatal rats prolonged the brainstem-to-cortex latencies from $20 \mathrm{~d}$ on (38). These findings are in line with our observation that $\mathrm{T} 4$ values $>200 \mathrm{nmol} / \mathrm{L}$ retarded the rate of maturation of the SEP in the period thereafter, suggesting a loss of "maturational capacity."

T4 values showed no direct relationship with the SEP parameters. Instead, a relation was found between earlier T4 status and later SEP development. This supports the hypothesis (13) that SEP reflects the maturational changes brought about by $\mathrm{CHT}$ and treatment, rather than the actual T4 status. This makes the SEP unsuitable for direct monitoring of therapy. 
In conclusion, we found that most, but not all, SEP abnormalities present at the beginning of therapy in patients with primary CHT were reversible. The central parts of the nervous system were more sensitive to changes in T4 than the peripheral parts. Adverse factors for the central SEP development were a slow initial T4 rise during induction and high T4 levels later on. Induction of therapy with $1-\mathrm{T} 3$ had the same protective effect as a rapid T4 induction. CHT patients with a total deficiency in T4 production were more at risk for inadequate treatment than patients with a partial deficiency. Our data support the view that early diagnosis and adequate treatment may prevent to some extent the minor neurologic dysfunctions observed in older CHT infants. Both under- and overtreatment seem harmful in this respect.

\section{REFERENCES}

1. Rovet J, Ehrlich R, Sorbara D 1987 Intellectual outcome in children with fetal hypothyroidism. J Pediatr 110:700-704

2. Glorieux J, Desjardins M, Letarte J, Morissette J, Dussault JH 1988 Useful parameters to predict the eventual mental outcome of hypothyroid children. Pediatr Res 24:6-8

3. Kalverboer AF, Bleeker JK 1988 De mentale en psychomotorische ontwikkeling van bij vroege screening ontdekte patientjes met congenitale hypothyreoidie. Ned Tijdschr Geneeskd 132:539-544

4. Komianou F, Makaronis G, Lambadaridis J, Sarafidou E, Vranchni F, Mengreli C, Pantelakis S 1988 Psychomotor development in congenital hypothyroidism. Eur J Pediatr 147:275-278

5. New England Congenital Hypothyroidism Collaborative 1984 Characteristics of infantile hypothyroidism discovered on neonatal screening. J Pediatr 104:539-544

6. Ilicki A, Larsson A 1988 Psychomotor development of children with congenital hypothyroidism diagnosed by neonatal screening. Acta Paediatr Scand 77:142-147

7. Fisher DA, Foley BL 1989 Early treatment of congenital hypothyroidism. Pediatrics 83:785-789

8. Penfold JL, Simpson DA 1975 Premature craniosynostosis: a complication of thyroid replacement therapy. J Pediatr 86:360-363

9. Rovet JF, Ehrlich RM, Sorbara D-L 1989 Effect of thyroid hormone level on temperament in infants with congenital hypothyroidism detected by screening of neonates. J Pediatr 114:63-68

10. Bongers-Schokking JJ, Colon EJ, Hoogland RA, de Groot CJ, Van den Brande JL 1991 Somatosensory evoked potentials in neonates with primary hypothyroidism during the first week of therapy. Pediatr Res 30:34-39

11. Hébert A, Laureau E, Vanasse M, Richard J-E, Morisette J, Glorieux J, Desjardins M, Letarte J, Dussault JH 1986 Auditory brain-stem response audiometry in congenitally hypothyroid children under early replacement therapy. Pediatr Res 20:570-573

12. Laureau E, Vanasse M, Hébert R, Letarte J, Glorieux J, Desjardins M, Dussault JH 1986 Somatosensory evoked potentials in congenital hypothyroidism. I. A longitudinal study before and after treatment in six infants detected in the neonatal period. Electroencephalogr Clin Neurophysiol 64:501-510

13. Hrbek A, Fallstrom SP, Karlberg P, Olsson T 1982 Clinical application of evoked EEG responses in infants. III. Congenital hypothyroidism. Dev Med Child Neurol 24:164-172

14. Vulsma T, Gons MH, de Vijlder JJM 1986 The etiology of CHT in the Netherlands. Ann Endocrinol (Paris) 47:79(abstr)

15. Fisher DA 1973 Advances in the laboratory diagnosis of thyroid disease. Part I. J Pediatr 82:1-9
16. Abuid J, Klein AH, Foley TP, Larsen PR 1974 Total and free triiodothyronine and thyroxine in early infancy. J Clin Endocrinol Metab 39:263-268

17. Stubbe P, Gatz J, Heidemann P, v. z. Muhlen A, Hesch R 1978 Thyroxinebinding globulin, triiodothyronine, thyroxine and thyrotropin in newborn infants and children. Horm Metab Res 10:58-61

18. Bongers-Schokking JJ, Colon EJ, Hoogland RA, Van den Brande JL, de Groot CJ 1989 The somatosensory evoked potentials of normal infants. Influence of filter bandpass, arousal state and number of stimuli. Brain Dev 11:33-39

19. Bongers-Schokking JJ, Colon EJ, Hoogland RA, Van den Brande JL, de Groot CJ 1990 Somatosensory evoked potentials in term and preterm infants in relation to postconceptional age and birth weight. Neuropediatrics $21: 32-36$

20. Dixon WJ 1990 BMDP Statistical Software Manual, Vol 2, Module 5V. University of California Press, Berkeley, CA

21. Gorke W 1986 Somatosensory evoked cortical potentials indicating impaired motor development in infancy. Dev Med Child Neurol 28:633-641

22. Giroud M, Tenenbaum D, D'Athis Ph, Dumas R, Nivelon JL 1988 L'exploration neuro-physiologique des nerfs péripheriques des nouveau-nés porteurs d'une hypothyreoidie congénitale. Arch Fr Pediatr 45:175-179

23. Vulsma T, Gons MH, de Vijlder JJM 1989 Maternal-fetal transfer of thyroxine in congenital hypothyroidism due to a total organification defect of thyroid agenesis. N Engl J Med 321:13-16

24. Laureau E, Hebert R, Vanasse M, Letarte J, Glorieux J, Desjardins M, Dussault JH 1986 Somatosensory evoked potentials in congenital hypothyroidism. II. A cross-sectional study in childhood. Correlations with hormonal levels and developmental quotients. Electroencephalogr Clin Neurophysiol 67:521-530

25. Klimach VJ, Cooke RW 1988 Maturation of the neonatal somatosensory evoked response in preterm infants. Dev Med Child Neurol 30:208-214

26. Ruiz de Oña C, Obregón MJ, Escobar del Rey F, Morreale de Escobar G 1988 Developmental changes in rat brain 5'deiodinase and thyroid hormones during the fetal period: the effects of fetal hypothyroidism and maternal thyroid hormones. Pediatr Res 24:588-594

27. Krawiec L, Garcia Argiz CA, Gomez CJ, Pasquini JM 1969 Hormonal regulation of brain development. III Effects of triiodothyronine and growth hormone on the biochemical changes in the cerebral cortex and cerebellum of neonatally thyroidectomized rats. Brain Res 15:209-218

28. van Doorn J, van der Heide D, Roelfsema F 1984 The contribution of local thyroxine monodeiodination to intracellular 3,5,3'-triiodothyronine in several tissues of hyperthyroid rats at isotopic equilibrium. Endocrinology 115:174-182

29. New England Congenital Hypothyroidism Collaborative 1990 Elementary school performances of children with congenital hypothyroidism. J Pediatr 116:27-32

30. Germak JA, Foley TP 1990 Longitudinal assessment of L-thyroxine therapy for congenital hypothyroidism. J Pediatr 117:211-219

31. Nakajima I, Inomata T 1984 Approaches to therapy for congenital hypothyroidism detected by neonatal screening. In: Naruse $\mathrm{H}$, Irie $\mathrm{M}$ (eds) Neonatal Screening. Excerpta Medica, Amsterdam, pp 157-162

32. Guyda HJ 1980 Therapy of congenital hypothyroidism. In: Burrow GN (ed) Neonatal Thyroid Screening. Raven Press, New York, pp 247-261

33. Herrera E, Escobar del Rey F, Morreale de Escobar G 1963 Effect of propylthiouracil on the in vivo deiodination of thyroxine labeled with ${ }^{131} I$ in different positions. Endocrinology 73:744-750

34. Obregón MJ, Morreale de Escobar G, Escobar del Rey F 1978 Concentrations of triiodo-L-thyronine in the plasma and tissues of normal rats as determined by radioimmunoassay: comparison with results obtained by an isotopic equilibrium technique. Endocrinology 103:2145-2153

35. Ferreiro B, Bernal J, Morreale de Escobar G, Potter BJ 1988 Preferential saturation of brain 3,5,3'-triiodothyronine receptor during development in fetal lambs. Endocrinology 133:438-443

36. Daneman D, Howard NJ 1980 Neonatal thyrotoxicosis: intellectual impairment and craniosynostosis in later years. J Pediatr 97:257-259

37. Kopelman AE 1983 Delayed cerebral development in twins with congenital hyperthyroidism. Am J Dis Child 137:842-845

38. Salas M, Diaz S, Cintra L 1976 Electrocortical effect of early postnatal thyroxine administration in the rat. Physiol Behav 17:239-244 